\title{
A comparative study between rheumatoid arthritis and osteoarthritis regarding association of insomnia with disease status
}

\author{
Rasha M. Fawzy*, Samia M. Abdel-Monem, Abdel-Wahab S. El-Brashi and Asmaa A. Mohamed
}

\begin{abstract}
Background: Sleep disturbance is closely related to inflammation and pain. Good sleep quality is essential for patients' psychological and physical states as well as their quality of life. The aim of this study was to detect how insomnia as a major sleep disturbance could add to the disease burden in rheumatoid arthritis (RA) and osteoarthritis patients $(\mathrm{OA})$ and to determine the predictor parameters in each of them in order to orient the rheumatologist to this unnoticed symptom that could adversely affect the patients'life. This study included: 20 RA patients, 20 primary knee OA patients together with 20 healthy controls. RA disease activity was assessed by the disease activity score (DAS28). All participants were assessed for sleep disturbances by the Athens Insomnia Scale, quality of life (QoL) using the short form QoL (SF-36 QoL) scale, depression by the Beck depression inventory (BDI), and functional disability by the Health Assessment Questionnaire Disability Index (HAQ-DI). OA patients were assessed by the Knee OA Flare Up Score (KOFUS) and the Western Ontario and McMaster Universities Arthritis Index (WOMAC). Radiological evaluation for RA patients was done by the Simple Erosion Narrowing Score, while the Kellgren and Lawrence (K-L) radiological grading system was used for OA patients.
\end{abstract}

Results: Insomnia was found in $75 \%$ of the studied RA patients, $25 \%$ of the studied OA patients and none of the healthy control with significant difference $(P<0.001)$. Significant correlations of the insomnia scale with the number of tender and swollen joints ( $r=0.66,0.76$ respectively and $p=0.001$ both), DAS-28 ( $r=0.71, P<0.001$ ), anti-CCP antibodies titre $(r=0.53, p=0.02)$ and the $\mathrm{BDI}(r=0.65, p=0.002)$ among RA patients were found. Correlations among OA patients occurred with morning stiffness duration $(r=0.69, P=0.001)$, number of affected joints $(r=0.81, P=0.001)$, the BDI scale $(r=0.51, P=0.02)$, the WOMAC index $(r=0.57, P=0.009)$, the KOFUS score $(r=0.76, p<0.001)$ and the $\mathrm{K}$-L score $(r=0.67, P=0.001)$. Linear regression analysis indicated that the predictors for insomnia in RA were DAS-28 and the BDI, while in OA were the number of affected joints and the KOFUS score.

Conclusions: Insomnia is a disease burden especially in RA patients being one of the leading causes of depression and is greatly affected by the disease activity. In general the burden of insomnia is much less in OA except in severe cases with markedly affected joints. Rheumatologists should be aware of this disorder that could affect patients' health, mood, and functional activity.

Keywords: Rheumatoid arthritis, Osteoarthritis, Sleep disturbance, Insomnia, Depression

*Correspondence: Dr.rasha.fawzy@hotmail.com

Rheumatology, Rehabilitation \& Physical Medicine, Faculty of Medicine, Benha University, Kalyoubia, Egypt

\section{Background}

Rheumatoid arthritis (RA) is the most common form of autoimmune systemic polyarticular diseases characterized by persistent synovial inflammation, bony erosions, and progressive articular destruction [1]. 
Sleep problems is a common clinical condition and has been considered an area of interest in chronic rheumatic diseases including RA [2]. Obstructive sleep apnea (OSA) is commonly associated with the Egyptian RA patients [3]. A large cohort study reported that the risk of autoimmune diseases has been increased in patients with non-apnea sleep disorders including RA, systemic lupus erythematosus, ankylosing spondylitis, and Sjögren's syndrome [4]. Among patients with OSA, the overall risk for RA is reported to be as high as 50\% [5]. The incidence of OSA was also higher among Behcet's disease and Sjögren's syndrome patients than in the controls [6]. Sleep disturbances do not only affect adult cases but also affect juvenile idiopathic arthritis (JIA) [7].

Investigators have found frequent awakenings, low sleep efficiency, sleep fragmentation, and reduced sleep quality among RA patients [8] which is closely linked to inflammation, pain, active disease status associated comorbidities, depressive mood, and medications [9]. However, to identify which one is the primary problem is difficult [10].

Exacerbated inflammation and inflammation-related symptoms, mental and/or physical fatigue, reduced daily activity [11] augmented perception of pain, mood disorders, and daytime sleepiness are consequences of impaired sleep and inevitably impair quality of life (QoL) of the affected patients [12].

Osteoarthritis $(\mathrm{OA})$ is a combined degenerative, and inflammatory disorder of joints associated with joint pain, edema, stiffness, and diminished joint function. The primary cause that patients with OA seek treatment is pain which negatively affects the patient's physical and psychologic state, making patients susceptible particularly to comorbid disorders such as sleep disturbances that may worsen OA-associated symptoms [13]. Epidemiologic surveys concluded that at least $50 \%$ of OA patients complained from difficulties to initiate or maintain sleep [14].

The aim of this study was to detect how insomnia could add to the disease burden in rheumatoid arthritis (RA) and osteoarthritis patients (OA) and to determine the predictor parameters in each of them in order to orient the rheumatologist to this unnoticed symptom that could adversely affect the patients' life.

\section{Methods}

\section{Study design}

This is a comparative study done between December 2020 and May 2021, included twenty RA patients older than 16 years diagnosed according to the American College of Rheumatology/ European League against Rheumatism (ACR/EULAR) 2010 criteria [15] (Group I). Twenty primary knee OA patients, who fulfilled the criteria of the American College of Rheumatology (ACR) [16] comprised Group II.

These patients were recruited from the attendants of the inpatients and the outpatients' clinic of the Rheumatology, Rehabilitation and Physical Medicine Department, Benha University Hospitals.

Twenty apparently healthy subjects were recruited from the hospital personnel and relatives of patients as a control group (Group III). Patients and controls were chosen age- and sex-matched.

The study was approved by the local ethical committee of Benha Faculty of Medicine. All enrolled participants gave an informed written consents prior to participation in this study.

\section{Exclusion criteria}

Age $<16$ years, obese patients, other autoimmune diseases, infections, fibromyalgia, diabetes mellitus, cancer, hypertension, systemic illnesses (respiratory, cardiovascular, gastrointestinal, endocrine disorders including patients with thyroid disturbances, renal, or neuropsychiatric). Patients receiving drugs that might interfere with sleep including analgesics, hypnotics, antidepressants, and muscle relaxants.

Patients' medical history was obtained, and clinical examination data were recorded. Disease activity of each RA patient was evaluated using the disease activity score of joint count (DAS-28) [17]. OA disease activity was assessed by the Knee Osteoarthritis Flare Up Score (KOFUS) [18], while OA disease severity was assessed using the Western Ontario and McMaster Universities Arthritis Index (WOMAC) [19].

The following laboratory investigations were done: a complete blood picture: by a the Sysmex 5000 counter, the erythrocyte sedimentation rate (ESR) by the Westergren method recorded in $\mathrm{mm} / \mathrm{hr}$. C-reactive protein (CRP) by quantitative nephelometry, liver enzymes and kidney function tests [serum creatinine and blood urea nitrogen (BUN) levels].

For RA patients we measured: the rheumatoid factor (RF) by the latex agglutination slide test, and the anticyclic citrullinated peptide (CCP) antibodies by ELISA were also requested.

Structural radiographic changes for RA patients were evaluated by plain postero-anterior view of both hands and both feet, with assessment of radiological severity using the Simple Erosion Narrowing Score (SENS). The total score ranges between 0 and 86 [20].

For OA patients, plain radiographs of both knees (weight-bearing antero-posterior and lateral views) were obtained, and radiographic severity of the OA was determined according to the Kellgren and Lawrence grading system [21]. 
All patients and subjects were asked to complete the following assessment scores:

The Athens Insomnia Scale [22] which evaluates insomnia severity using the diagnostic criteria set forth by the International Classification of Diseases (ICD10). This questionnaire involves eight-item evaluates sleep onset, night and early-morning awakening, time of sleep, quality of sleep, frequency and the duration of complaints, distress induced by the experience of insomnia and interference with daily functioning. Scores range from 0 to 3 where score 0 indicates that the item in question has not been a problem and score 3 means more acute sleep difficulties. [A score of 0-6 indicates no insomnia, 6-12 indicates mild insomnia, 12-18 indicates moderate insomnia, and a score of 18-24 indicates severe insomnia].

- Assessment of the quality of life using the Short Form Quality of life (SF-36 QoL) scale [23].

- Associated depression was evaluated by the Beck Depression Inventory (BDI) [24].

- Patients' functional ability was assessed using the Health Assessment Questionnaire (HAQ) [25].

\section{Statistical analysis}

The tabulated data were coded then analyzed by the computer program SPSS (Statistical package for Social Science) version. Categorical data were presented as number and percentages while quantitative data were expressed as mean \pm standard deviation, median, range, and IQR. ANOVA (analysis of variance) was used to compare between more than two groups of numerical (parametric) data, for continuous non-parametric data; for inter-group analysis, post hoc analysis was used. Chi-square test and Fisher's exact test were used for inter-group comparison of categorical data. Correlating different parameters was done by Pearson and Spearman's correlation coefficient (r) test. To determine which of the investigated parameters considered as a significant predictor, they were entered into regression mode. $P$ value $\leq 0.05$ was considered statistically significant (S).

\section{Results}

This study was conducted on 20 RA patients (group I), 16 females $(80 \%)$ and 4 males (20\%), with ages ranging from 30 to 60 years (mean \pm SD $41.69 \pm 6.29$ years). Group II primary knee OA patients were 16 females $(80 \%)$ and 4 males (20\%) with ages ranging from 30 to 60 years (mean \pm SD age of $43.24 \pm 6.54$ years). The control group (group III) comprised 13 females (65\%) and 7 males (35\%) with ages ranging from 31 to 60 years (mean \pm SD age of $39.91 \pm 4.29$ years).
Patients and subjects in the three groups showed no differences among them regarding their ages and sex. Characteristics of the studied groups are expressed in Table 1.

Insomnia was considered at a score 26 of the Athens Insomnia Scale. Fifteen of RA patients (75\%) had insomnia, 5 OA patients (25\%) had insomnia while none of the controls $(0 \%)$ had insomnia with statistical significant difference $(p=<0.001)$. In RA, 8 patients $(40 \%)$ had mild insomnia, 6 patients (30\%) had moderate insomnia, 1 patient $(5 \%)$ had severe insomnia, while 5 patients $(25 \%)$ had no insomnia. While among OA patients, $5(25 \%)$ had mild insomnia.

The Athens Insomnia Scale was highest in RA patients and showed a highly statistically significant difference

Table 1 Characteristics of the studied rheumatoid arthritis patients and osteoarthritis patients

\begin{tabular}{|c|c|c|}
\hline Characteristics & RA patients & OA patients \\
\hline $\begin{array}{l}\text { Disease duration (years) } \\
\text { median (IQR) }\end{array}$ & $8(5-15.5)$ & $7(4-14.5)$ \\
\hline $\begin{array}{l}\text { Duration of morning stiffness/minutes } \\
\text { median (IQR) }\end{array}$ & $60(60-120)$ & $22.5(17.5-30)$ \\
\hline $\begin{array}{l}\text { Tender joints } \\
\text { median (IQR) }\end{array}$ & $9(5-16)$ & $3(2-5)$ \\
\hline $\begin{array}{l}\text { Swollen joint } \\
\text { median (IQR) }\end{array}$ & $6(3-8)$ & - \\
\hline Rheumatoid nodules no. (\%) & $11(55)$ & - \\
\hline Chest symptoms no. (\%) & $2(10)$ & - \\
\hline Sicca symptoms no. (\%) & $2(10)$ & - \\
\hline Hemoglobin (g/dl) & $11.35 \pm 1.35$ & $12.2 \pm 1.5$ \\
\hline $\begin{array}{l}\mathrm{ESR}(\mathrm{mm} / \mathrm{h}) \\
\text { median }(\mathrm{IQR})\end{array}$ & $47.4(33.8-78.8)$ & $20(11.25-25)$ \\
\hline $\begin{array}{l}\mathrm{CRP}(\mathrm{mg} / \mathrm{L}) \\
\text { median }(\mathrm{IQR})\end{array}$ & $9(5.8-48)$ & $5(3.2-26)$ \\
\hline $\begin{array}{l}\text { RF titre } \\
\text { median (IQR) }\end{array}$ & $64(28-128)$ & - \\
\hline $\begin{array}{l}\text { Anti-CCP titre } \\
\text { median (IQR) }\end{array}$ & $65(25.8-205)$ & - \\
\hline $\begin{array}{l}\text { DAS } 28 \\
\text { median (IQR) }\end{array}$ & $4.8(4.02-5.2)$ & - \\
\hline $\begin{array}{l}\text { Simple Erosion Narrowing score median } \\
(\mathrm{IQR})\end{array}$ & $19(12.3-31.5)$ & - \\
\hline \multicolumn{3}{|l|}{ Kellgren-Lawrence } \\
\hline Grade I & - & $2(10)$ \\
\hline Grade II & - & $10(50)$ \\
\hline Grade III & - & $7(35)$ \\
\hline Grade IV & - & $1(5)$ \\
\hline WOMAC median (IQR) & - & $34.5(24.5-44)$ \\
\hline KOFUS median (IQR) & - & $3(2-5)$ \\
\hline
\end{tabular}

ESR Erythrocyte sedimentation rate, CRP C-reactive protein, $R F$ Rheumatoid factor, Anti-CCP Anti-cyclic citrullinated peptide, WOMAC Western Ontario and McMaster Universities Osteoarthritis Index, KOFUS Knee Osteoarthritis Flare-Ups Score 
compared to OA patients $(p<0.001)$ and controls $(p$ $<0.001)$, meanwhile the difference was insignificant between OA patients and the controls $(p=0.22)$, Table 2 .

Among the 8 items included in The Athens Insomnia Scale in RA patients, the most reported symptom was detected is disturbance in induction of sleep $(11 / 20)$.

Among the studied RA patients, 2 cases $(10 \%)$ had a low disease activity, 11 patients (55\%) had a moderate disease activity, and 7 cases (35\%) had a high disease activity. The median Athens Insomnia Scale was

Table 2 Comparisons among the studied groups regarding the mean Athens Insomnia Scale

\begin{tabular}{lllll}
\hline & $\boldsymbol{N}$ & Mean \pm SD & P value & Post-hoc test \\
\hline RA patients & 20 & $9.85 \pm 4.793$ & $<\mathbf{0 . 0 0 1}$ & $\mathbf{P} 1<\mathbf{0 . 0 0 1} \mathbf{1}^{* *}$ \\
OA patients & 20 & $2.50 \pm 2.373$ & & $\mathbf{P} 2<\mathbf{0 . 0 0 1}$ ** $^{*}$ \\
Control group & 20 & $1.25 \pm 1.209$ & & $\mathrm{P} 3=0.22$
\end{tabular}

$P 1$ RA vs OA, $P 2$ RA vs controls, $P 3$ OA vs controls; $p \geq 0.05=$ non-significant, $p \leq$ $0.001^{* *}=$ highly significant. One-way ANOVA $(f)$ test and post hoc analysis higher among RA patients with a high disease activity (14) grade compared to patients with a moderate (8) or a low disease activity (6.5) with a significant difference among the insomnia grades $(p=0.04)$.

RA patients with moderate and severe insomnia scale had a significantly higher tender and swollen joints numbers, anti-CCP titres and DAS-28 compared to patients with a mild disease activity $(p<$ $0.001, p=0.013, p=0.004$, and $p<0.001$ respectively) (Table 3).

- Table 4 shows correlations of different disease variables in RA and OA patients with the Athens Insomnia Scale grading.

- Tables 5 and 6 shows regression analysis for the predication of insomnia among the studied RA and OA patients.

Table 3 Comparisons of the mean The Athens Insomnia Scale grading regarding the different disease parameters among the studied RA patients

\begin{tabular}{|c|c|c|c|c|}
\hline Variables & None $(n=5)$ & Mild $(n=8)$ & Moderate/severe $(n=7)$ & $P$ value \\
\hline $\begin{array}{l}\text { Age (years) } \\
\text { (mean } \pm S D)\end{array}$ & $40.8 \pm 8.89$ & $47.25 \pm 8.84$ & $42.29 \pm 8.99$ & 0.395 \\
\hline \multicolumn{5}{|l|}{$\begin{array}{l}\text { Sex } \\
\text { no. (\%) }\end{array}$} \\
\hline Female & $3(60)$ & $6(75)$ & $7(100)$ & 0.21 \\
\hline Male & $2(40)$ & $2(25)$ & $0(0)$ & \\
\hline $\begin{array}{l}\text { Disease duration } \\
\text { Median (IQR) }\end{array}$ & $6(4-12)$ & $11.5(6.5-18.5)$ & $5(2-15)$ & 0.350 \\
\hline $\begin{array}{l}\text { Morning stiffness/minutes } \\
\text { median (IQR) }\end{array}$ & $60(60-90)$ & $120(60-120)$ & $120(60-120)$ & 0.371 \\
\hline $\begin{array}{l}\text { Tender joints } \\
\text { median (IQR) }\end{array}$ & $3(2-6)$ & $6.5(3-9.25)$ & $12(10-15)$ & $<0.001^{* *}$ \\
\hline $\begin{array}{l}\text { Swollen joint } \\
\text { median (IQR) }\end{array}$ & $1(0-1)$ & $1(0-3.75)$ & $4(2-5)$ & $0.013^{* *}$ \\
\hline Rheumatoid nodules no. (\%) & $1(20)$ & $5(62.5)$ & $5(71.4)$ & 0.2 \\
\hline Chest symptoms. (\%) & $0(0)$ & $2(25)$ & $0(0)$ & 0.2 \\
\hline Sicca symptoms (\%) & $0(0)$ & $1(12.5)$ & $1(14.3)$ & 0.7 \\
\hline $\begin{array}{l}\text { DAS } 28 \\
\text { median (IQR) }\end{array}$ & $4.03(3.08-4.6)$ & $4.4(3.9-5.1)$ & $5.3(5.04-6.1)$ & $0.004^{* *}$ \\
\hline $\begin{array}{l}\text { Simple Erosion Narrowing Score } \\
\text { median (IQR) }\end{array}$ & $18(10-28)$ & $21(13.3-36.5)$ & $20(11-30)$ & 0.659 \\
\hline Hemoglobin (g\dl) & $11.8 \pm 1.6$ & $11.4 \pm 1.3$ & $11.01 \pm 1.4$ & 0.63 \\
\hline ESR median (IQR) & $45(23.5-70)$ & $47.5(31.25-107.5)$ & $70(30-90)$ & 0.64 \\
\hline CRP median (IQR) & $6(3.5-38.5)$ & $12(6-42)$ & $6(5-48)$ & 0.95 \\
\hline RF median (IQR) & $64(14-173)$ & $64(20-117)$ & $128(64-128)$ & 0.71 \\
\hline $\begin{array}{l}\text { Anti-CCP } \\
\text { median (IQR) }\end{array}$ & $30(20-139)$ & 30 (19-90) & $265(145-355.5)$ & $<0.001^{* *}$ \\
\hline
\end{tabular}

ESR Erythrocyte sedimentation rate, $C R P$ C-reactive protein, $R F$ Rheumatoid factor, Anti-CCP Anti-cyclic citrullinated peptide. $p \geq 0.05=$ non-significant, $p \leq 0.001 * *=$ highly significant. One-way ANOVA ( $f$ ) test, Fisher's exact test, chi-square test 
Table 4 Correlations of the Athens Insomnia scale with different variables of RA patients and OA patients

\begin{tabular}{|c|c|c|}
\hline Variable & $\begin{array}{l}\mathrm{RA} \\
r(p)\end{array}$ & $\begin{array}{l}\mathrm{OA} \\
r(p)\end{array}$ \\
\hline Patients'age & $0.012(0.96)$ & $0.41(0.069)$ \\
\hline Disease duration & $-0.051(0.83)$ & $0.34(0.13)$ \\
\hline Morning stiffness & $0.407(0.07)$ & $0.69(\mathbf{0 . 0 0 1 * *})$ \\
\hline No. of tender joints & $0.668^{* *}\left(<0.0011^{* *}\right)$ & $0.81(\mathbf{0 . 0 0 1})^{* *}$ \\
\hline No. of swollen joints & $0.673^{* *}\left(<0.001^{* *}\right)$ & - \\
\hline DAS-28 & $0.71\left(<0.001^{* *}\right)$ & - \\
\hline Hemoglobin & $-0.031(0.18)$ & $-0.32(0.17)$ \\
\hline ESR & $0.36(0.11)$ & $0.41(0.07)$ \\
\hline CRP & $0.18(0.42)$ & - \\
\hline RF & $0.19(0.41)$ & - \\
\hline Anti-CCP antibodies & $0.53 *(\mathbf{0 . 0 2}) *$ & - \\
\hline $\begin{array}{l}\text { Short Form Quality of Life } \\
\text { SF-36 }\end{array}$ & $-0.02(0.92)$ & $-0.43(0.060$ \\
\hline Beck Depression Inventory & $0.65(\mathbf{0 . 0 0 2}) * *$ & $0.51^{*}(\mathbf{0 . 0 2}) *$ \\
\hline HAQ-DI & $0.03(0.89)$ & $0.37(0.10)$ \\
\hline $\begin{array}{l}\text { Simple Erosion Narrowing } \\
\text { score }\end{array}$ & $-0.008(0.97)$ & \\
\hline WOMAC & - & $0.57^{*}(0.009)$ \\
\hline KOFUS & - & $0.761^{*}\left(<0.001^{* *}\right)$ \\
\hline Kellgren-Lawrence grades & - & $0.675^{*}(\mathbf{0 . 0 0 1}) * *$ \\
\hline
\end{tabular}

ESR Erythrocyte sedimentation rate, CRP C-reactive protein, $R F$ Rheumatoid factor, Anti-CCP Anti-cyclic citrullinated peptide, HAQ-DI Health Assessment Questionnaire Disability Index, WOMAC Western Ontario and McMaster Universities Osteoarthritis Index, KOFUS Knee Osteoarthritis Flare-Ups Score. $p \geq 0.05=$ non-significant, $p \leq 0.001^{* *}=$ highly significant. Spearman correlation and Pearson coefficient

Table 5 Regression analysis for the prediction of the Athens Insomnia scale grading in RA patients

\begin{tabular}{lllll}
\hline RA $(\boldsymbol{n = 2 0 )}$ & Beta & $\boldsymbol{P}$ value & $\begin{array}{l}\mathbf{9 5 . 0 \%} \text { confidence interval } \\
\text { for B }\end{array}$ \\
\cline { 3 - 5 } & & & Lower bound & Upper bound \\
\hline Tender joints & 0.30 & 0.390 & -0.41 & 0.97 \\
Swollen joints & 0.25 & 0.45 & -1.14 & 2.57 \\
Anti-CCP titre & 0.20 & 0.28 & -0.01 & 0.03 \\
DAS 28 & 0.12 & $\mathbf{0 . 0 0 3 * *}$ & 1.29 & 5.25 \\
Beck depression inven- & 0.31 & $\mathbf{0 . 0 1} *$ & 0.01 & 0.53 \\
tory & & & & \\
\hline
\end{tabular}

$p \geq 0.05=$ non-significant, $p \leq 0.001^{* *}=$ highly significant

\section{Discussion}

Sleep strongly regulates the immune system functions. Sleep deprivation not only cause disturbance of the immunity resulting in the suppression of the body's response to pathogens but also result in the collapse of the immunological self-tolerance, which can trigger the onset of autoimmune disease [26].
Table 6 Regression analysis for the prediction of the Athens Insomnia scale grading in OA patients

\begin{tabular}{lllll}
\hline OA $(\boldsymbol{n}=\mathbf{2 0})$ & Beta & $\boldsymbol{P}$ value & $\begin{array}{l}\mathbf{9 5 . 0 \%} \text { confidence interval } \\
\text { for B }\end{array}$ \\
\cline { 5 - 5 } & & & Lower bound & Upper bound \\
\hline Morning stiffness & 0.14 & 0.59 & -0.12 & 0.21 \\
Affected joints & 0.82 & $<\mathbf{0 . 0 0 1 * *}$ & 0.57 & 1.18 \\
$\begin{array}{l}\text { Beek depression } \\
\text { inventory }\end{array}$ & 0.06 & 0.77 & -0.23 & 0.31 \\
WOMAC & 0.14 & 0.47 & -0.05 & 0.10 \\
KOFUS & 0.67 & $\mathbf{0 . 0 4}$ & 0.01 & 1.33 \\
Kellegren-Lawrence & 0.32 & 0.68 & -1.29 & 1.94 \\
\hline
\end{tabular}

$p \geq 0.05=$ non-significant, $p \leq 0.001^{* *}=$ highly significant

In this work where insomnia was recorded at ${ }^{>} 6$ on the Athens Insomnia Scale, about $75 \%$ of the included RA patients suffered from insomnia while only $25 \%$ of the studied OA patients and $0 \%$ of the healthy control group had insomnia with a statistically highly significant difference $(p>0.001)$. This is parallel to Abad et al. [27] who reported sleep disturbances in $54-70 \%$ of their RA patients.

Numbers of insomniac RA patients were variable in the studies of Sariyildiz et al. [8] and Radwan and Borai [28], who reported that $64.1 \%$ and $54.1 \%$ of their RA patients respectively had a poor sleep quality, while in Goes et al. study, only $18.5 \%$ of RA patients reported a good quality of sleep [29].

In contrast to our findings among persons with knee OA, many authors reported up to $31 \%$ significant disturbances initiating sleep, and $81 \%$ had difficulties maintaining night-time sleep [14, 30].

Regarding the mean Athens Insomnia Scale, it was highest in RA patients and showed a highly statistically significant difference in comparison to OA patients ( $p$ $<0.001)$ and controls $(p<0.001)$, meanwhile the difference was insignificant between OA patients and the controls $(p=0.22)$. However, Kwiatkowska et al. reported that the difference between patients with RA and those with OA was not statistically significant [31].

Westhovens et al. [32] stated that the associated inflammation and active disease status are also responsible for a poor sleep quality in RA patients. Similarly, in the present study, RA patients with a higher disease activity status had a higher insomnia scale with a significant difference $(p=0.04)$ from other activity states (mild or moderate). Also, patients with moderate and severe insomnia had higher tender and swollen joint count and a higher DAS-28 than other RA patients. This coincided with that reported by Sariyildiz et al. [8] and Son et al. [33]. 
Some investigators reported increased circulating levels TNF $\alpha$ as an inflammatory cytokine among RA patients with sleep disorders. They also stated that levels of IL-1 in the brain and TNF $\alpha$ are related to sleep deprivation [34]. This hypothesis was further evinced by improvement of sleep quality after the use of anti-TNF medications [35] thus there may be a connection between the level of this cytokine and sleep disorders.

Regarding laboratory parameters in the present work, the anti-CCP antibodies level was significantly higher among RA patients with a higher insomnia scale grade $(p<0.001)$ with its level correlating positively with the insomnia scale $(r=0.53, p=0.02)$. This was comparable to Radwan and Borai [28]. However, this was inconsistent to the results stated by another Egyptian study [36].

In this work, no ESR significant differences $(p=0.64)$ were found among RA patients regarding different insomnia scale grading, while Radwan and Borai [28] and Sariyildiz et al. [8] reported that ESR values were connected to poor sleep quality. Lee et al. found the probability of a close association of elevated ESR with moderate or severe sleep apnea [10].

The present study showed insignificant association between the patients' ages and the insomnia scale either in RA or OA $(r=0.01, p=0.96$ and $r=0.41, p=0.06$ respectively). These results were similar to the results of other studies conducted on RA patients [28, 33]. However, a study on Egyptian RA patients reported a significant relation [36], while some authors have found a poor sleep quality in older patients [33-39].

Smith et al. stated that sleep disturbances are prevalent in painful rheumatologic conditions [37]. Among our studied RA and OA patients, we observed significant positive correlations of the insomnia scale with the tender joint count. This is explained as sleep disruption is documented to be a direct contributor to both hyperalgesia and impaired endogenous pain modulation [37].

In the current study among the studied RA patients, the insomnia scale demonstrated significant positive correlations with the swollen joint count $(r=0.67, p<0.001)$ and DAS-28 $(r=0.71, p<0.001)$, while among the studied OA patients significant positive correlations were reported with the duration of morning stiffness $(r=69$, $p=0.001)$, KOFUS score $(r=0.76, p=0.001)$ depression score $(r=0.51, p=0.02)$, WOMAC index $(r=0.57$, $p=0.009)$, and the Kellgren-Lawrence grades $(r=0.67$, $p=0.001$ ).

Sleep difficulties are also closely linked with the depressed mood. The higher depression score in RA patients is related to functional disability [28] and the quality of life [8]. In the present study, the insomnia scale correlated positively with the depression score $(r=0.31$, $p=0.01)$ in RA patients.
Wolfe et al. [38] reported that sleep disturbances are independently associated with pain and depression in RA, though Nicassio and Wallston [39] reported that sleep disturbances are associated with depression independently of pain, and that long-term pain is a predictor of deteriorating sleep disorders.

The SENS showed an insignificant negative correlation with the insomnia scale $(r=-0.008, p=0.97)$ which did not accord with Sariyildiz et al. [8] who reported that a higher radiological score correlated with a poor sleep quality. They explained their findings by the association between radiological grading and lower QoL that might contribute sleep quality. However, the Athens Insomnia Scale had also a negative insignificant correlation $(r=0.022, p=0.92)$ with the QoL.

In OA patients, there was a highly significant positive correlation of the Athens Insomnia Scale with the Kellgren-Lawrence grading $(r=0.675, p=0.001)$, while it showed a non-significant negative correlation with the QoL $(r=-43, p=0.06)$.

In RA patients, we did not find a correlation between morning stiffness duration and insomnia, although it was significant $(r=0.40, p=0.07)$ among OA patients. Other investigators reported that pain occurs at rest and stiffness of joints was considered to be factors linked to sleep disturbances [37].

After application of linear regression analysis; predictors of insomnia among RA patients were the activity status $(p=0.003)$ and depression $(p=0.01)$ which was similar to Sariyildiz et al. [8]. Radwan and Borai [28] added that functional disability was among the predictors for a poor sleep quality although Nicasso et al. [40] informed that depression but not disease activity contributes to poor sleep.

Limitations of the current study included the small number of the patients, lack of follow up to detect the effect of medications and the control of the disease on insomnia especially for those who reached the target during therapy.

\section{Conclusions}

Insomnia is a disease burden especially in RA patients being one of the leading causes of depression and is greatly affected by the disease activity. In general, the burden of insomnia is much less in OA except in severe cases with markedly affected joints. Rheumatologists should be aware of this disorder that could affect patients' health, mood, and functional activity.

Thus, we recommend parallel management should be introduced when insomnia is diagnosed in a group of patients with rheumatic disorders as it ensures increased therapeutic effectiveness for both diseases. 


\section{Abbreviations}

ESR: Erythrocyte sedimentation rate; CRP: C-reactive protein; RF: Rheumatoid factor; Anti-CCP: Anti-cyclic citrullinated peptide; HAQ-DI: Health Assessment Questionnaire Disability Index; WOMAC: Western Ontario and McMaster Universities Osteoarthritis Index; KOFUS: Knee Osteoarthritis Flare-Ups Score: SF-36 QoL: Short Form Quality of life scale; BDI: Beck Depression Inventory; DAS-28: Disease activity score.

\section{Acknowledgements}

We acknowledge all the participants and medical staff who helped us in this study.

\section{Authors' contributions}

Idea suggestion, put the study design: RF and SA. Data collection and analysis: RF and AM. Supervision and discussion: RF, SA, and AE. Manuscript writing and final revision: RF and SA. The content of the manuscript has not been published, or submitted for publication elsewhere. All authors have read and approved the manuscript.

\section{Funding}

This research did not receive any specific grant from funding agencies.

\section{Availability of data and materials}

The datasets used and/or analyzed during the current study are available from the corresponding author on reasonable request.

\section{Declarations}

Ethics approval and consent to participate

Done. The committee's reference number: MS 1310-2020, date: 13 October 2020. Written consents according to Helsinki Declaration were taken from all patients and control subjects prior to participation in the study that was approved by the ethical committee of Faculty of Medicine, Benha University.

\section{Consent for publication}

Not applicable.

\section{Competing interests}

The authors declare that they have no competing interests.

Received: 9 November 2021 Accepted: 14 December 2021

Published online: 25 January 2022

\section{References}

1. Alam SM, Kidwai AA, Jafri SR, Qureshi BM, Sami A, Qureshi HH (2011) et al. Epidemiology of rheumatoid arthritis in a tertiary care unit, Karachi, Pakistan. J Pak Med Assoc 61:123-126

2. Purabdollah M, Lakdizaji S, Rahmani A, Hajalilu M, Ansarin K (2015) Relationship between sleep disorders, pain and quality of life in patients with rheumatoid arthritis. J Caring Sci 4(3):233-241

3. Hammam N, Gamal R, Rashed A, Elfetoh N, Mosad E, Khedr E (2018) Fatigue in Rheumatoid Arthritis Patients: Association With Sleep Quality, Mood Status, and Disease Activity. Reumatol Clin (Engl Ed) 16(5 Pt 1):339344. https://doi.org/10.1016/j.reuma.2018.07.010

4. Hsiao Y, Chen YT, Tseng CM, Wu LA, Lin WC, Su VY et al (2015) Sleep disorders and increased risk of autoimmune diseases in individuals without sleep apnea. Sleep 38(4):581-586

5. Reading SR, Crowson CS, Rodeheffer RJ, Fitz-Gibbon PD, Maradit- Kremers H, Gabriel SE (2009) Do rheumatoid arthritis patients have a higher risk for sleep apnea? J Rheumatol 36(9):1869-1872

6. Chen WS, Chang YS, Chang CC, Chang DM, Chen YH, Tsai CY et al (2016) Management and risk reduction of rheumatoid arthritis in individuals with obstructive sleep apnea: a nationwide population-based study in Taiwan. Sleep 39:1883-1890

7. Tsipoura G, Lazaratou H, Damigos D, Vougiouka O (2018) Sleep and its relationship to health-related quality of life in children and adolescents with inactive juvenile idiopathic arthritis. Egypt Rheumatol 40(3):197-201
8. Sariyildiz MA, Batmaz I, Bozkurt M, Bez Y, Cetincakmak MG, Yazmalar L et al (2014) Sleep quality in rheumatoid arthritis: relationship between the disease severity, depression, functional status and the quality of life. J Clin Med Res 6:44-52

9. Anderson J, Caplan L, Yazdany J, Neogi T, Michaud K, Saag K et al (2012) Rheumatoid arthritis disease activity measures: American College of Rheumatology Recommendations for use in clinical practice. Arthritis Care Res (Hoboken) 64(5):640-647

10. Lee YC, Lu B, Edwards RR, Wasan AD, Nassikas NJ, Clauw DJ et al (2013) The role of sleep problems in central pain processing in rheumatoid arthritis. Arthritis Rheum 65:59-68

11. Alsafadi S, Abaalkhail B, Wali SO, Aljammali K, Alotaiby B, Zakaria I et al (2018) Risk factors of primary and secondary restless legs syndrome among a middle-aged population in SaudiArabia: a community-based study. Ann Thorac Med 13:175-181

12. Hennessy MD, Zak RS, Gay CL, Pullinger CR, Lee KA, Aouizerat BE (2013) Polymorphisms of interleukin-1 Beta and interleukin-17Alpha genes are associated with restless legs syndrome. Biol Res Nurs 16(2):143-151

13. Parmelee AP, Tighe AC, Dautovich DN (2015) Sleep disturbance in osteoarthritis: linkages with pain, disability, and depressive symptoms. Arthritis Care Res 67(3):358-365

14. Wilcox S, Brenes GA, Levine D, Sevic M (2000) Factors related to sleep disturbance in oder adults experiencing knee pain or knee pain with radiographic evidence of knee osteoarthritis. J Am Geriatr Soc 48:1241-1251

15. Aletaha D, Neogi T, Silman AJ, Funovits J, Felson DT, Bingham CO et al (2010) the 2010 rheumatoid arthritis classification criteria: an American College of Rheumatology/European League Against Rheumatism collaborative initiative. Ann Rheum Dis 69(9):1580-1588

16. Altman R, Asch E, Bloch D, Bole G, Borenstein D, Brandt K et al (1986) Development of criteria for the classification and reporting of osteoarthritis. Classification of osteoarthritis of the knee. Arthritis Rheum 29:1039-1049

17. Prevoo ML, van't Hof MA, Kuper HH, van Leeuwen MA, van de Putte LB et al (1995) Modified disease activity scores that include twenty-eightjoint counts. Development and validation in a prospective longitudinal study of patients with rheumatoid arthritis. Arthritis Rheum 38:44-48

18. Marty M, Hilliquin P, Rozenberg S, Valat JP, Coste P, Savarieau B, Allaert F et al (2009) Validation of the KOFUS (Knee Osteoarthritis Flare-Ups Score). Joint Bone Spine 76:268-272

19. McConnell S, Kolopack P, Davis AM (2001) The Western Ontario and McMaster Universities Osteoarthritis Index (WOMAC): a review of its utility and measurement properties. Arthritis Care Res 45:453-461

20. Van der Heijde D, Boonen A, Boers M, Kostense P, van der Linden S (1999) Reading radiographs in chronological order, in pairs or as single films has important implications for the discriminative power of rheumatoid arthritis clinical trials. Rheumatology Oxford 38:1213-1220

21. Kellgren JH, Lawrence JS (1975) Radiological assessment of osteoarthritis. Ann Rheum Dis 16:494-501

22. Soldatos CR, Dikeos D, Paparrigopoulos TJ (2003) The diagnostic validity of the Athens Insomnia Scale. J Psychosom Res 55(3):263-267

23. McHorney CA, Ware JE Jr, Raczek AE (1993) The MOS 36-Item ShortForm Health Survey (SF-36): II. Psychometric and clinical tests of validity in measuring physical and mental health constructs. Med Care 31:247-263

24. Richter P, Werner J, Heerleih A, Kraus A, Sauer H (1988) On the validity of the Beck Depression Inventory. A review. Psychopathology 31:160-168

25. Wolfe F, Kleinheksel SM, Cathey MA, Hawley DJ, Spitz PW, Fried JF (1988) The clinical value of the Stanford Health Assessment Questionnaire Functional Disability Index in patients with rheumatoid arthritis. J Rheumatol 15(10):1480-1488

26. Bollinger T, Bollinger A, Skrum L, Dimitrov S, Lange T, Solbach W (2009) Sleep-dependent activity of $T$ cells and regulatory $T$ cells. Clin Exp Immunol 155:231-238

27. Abad VC, Sarinas PS, Guilleminault C (2008) Sleep and rheumatologic disorders. Sleep Med Rev 12(3):211-228

28. Radwan A, Borai A (2020) Quality of sleep in rheumatoid arthritis patients: relationship with disease activity, depression and functional status. Egypt Rheumatol 43(1). https://doi.org/10.1016/j.ejr.2020.08.002

29. Goes A, Reis L, Silva M, Kahlow B, Skare L (2017) Rheumatoid arthritis and sleep quality. Rev Bras Reumatol Engl Ed 57(4):294-298 
30. Allen KD, Renner JB, Devellis B, Helmick CG, Jordan JM (2008) Osteoarthritis and sleep: the Johnston County Osteoarthritis Project. J Rheumatol 35:1102-1107

31. Westhovens R, Van der Elst K, Matthys A, Tran M, Gilloteau I (2014) Sleep problems in patients with rheumatoid arthritis. J Rheumatol 41 (1):31-40. https://doi.org/10.3899/jheum.130430

32. Westhovens R, Van der Elst K, Matthys A, Tran M, Gilloteau I (2014) Sleep problems in patients with rheumatoid arthritis. J Rheumatol 41:31-40

33. Son CN, Choi G, Lee SY, Lee JM, Lee TH, Jeong HJ et al (2015) Sleep quality in rheumatoid arthritis, and its association with disease activity in a Korean population. Korean J Intern Med 30(3):384-390

34. Krueger JM, Obal FJ, Faig J, Kubota T, Taishi P (2001) The role of cytokines in physiological sleep regulation. Ann N Y Acad Sci 933:211-221

35. Taylor-Gjevre RM, Gjevre JA, Nair BV, Skomro RP, Lim HJ (2011) Improved sleep efficiency after anti-tumor necrosis factor_therapy in rheumatoid arthritis patients. Ther Adv Musculoskelet Dis 3(5):227-233

36. Abd Elazeem MI, Salem MN (2018) Can rheumatoid arthritis affect sleep in Egyptian patients? Egypt Rheumatol 40(1):11-16

37. Smith MT, Quartana PJ, Okonkwo RM, Nasir A (2009) Mechanisms by which sleep disturbance contributes to osteoarthritis pain: a conceptual model. Curr Pain Headache Rep 13:447-454

38. Wolfe F, Michaud K, Li T (2006) Sleep disturbance in patients with rheumatoid arthritis: evaluation by medical outcomes study and visual analog sleep scales. J Rheumatol 33(10):1942-1951

39. Nicassio PM, Wallston KA (1992) Longitudinal relationships among pain, sleep problems, and depression in rheumatoid arthritis. J Abnorm Psychol 101(3):514-520

40. Nicassio PM, Ormseth SR, Kay M, Custodio M, Irwin MR, Olmstead R et al (2012) The contribution of pain and depression to self-reported sleep disturbance in patients with rheumatoid arthritis. Pain 153(1):107-112

\section{Publisher's Note}

Springer Nature remains neutral with regard to jurisdictional claims in pub-

lished maps and institutional affiliations.

\section{Submit your manuscript to a SpringerOpen ${ }^{\odot}$ journal and benefit from:}

- Convenient online submission

- Rigorous peer review

- Open access: articles freely available online

- High visibility within the field

- Retaining the copyright to your article

Submit your next manuscript at $\gg$ springeropen.com 